\title{
VOKAL BAHASA BUDONG-BUDONG
}

\author{
Mardi Nugroho \\ Badan Pengembangan dan Pembinaan Bahasa \\ Pos-el: mardinugroho16@gmail.com
}

\begin{abstract}
A bstrak
Bahasa Budong-Budong merupakan bahasa yang hampir punah. Bahasa Budong-Budong jumlah penuturnya 70 orang. Oleh karena itu, bahasa ini selayaknya diprioritaskan untuk dikonservasi. Contoh upaya yang termasuk dalam program konservasi ialah penyusunan sistem fonologi, morfologi, sintaksis, dan sistem aksaraatau ortografi. Masalah dal am penelitian ini ialah vokal apa saja yang terdapat dalam bahasa Budong-Budong. Tujuan penelitian ini ialah menemukan vokalvokal yang terdapat dalam bahasa Budong-Budong dan alofon-al ofonnyayang diharapkan berguna dalam upaya penyusunan sistem fonologinya. Metodeyang digunakan dalam penelitian ini bersifat deskriptif. Pengumpulan data dilakukan dengan wawancara dan perekaman. Pengolahan data dilakukan dengan metode padan (alat penentunya referen dan lawan bicara) dan metode distribusional (dengan teknik oposisi pasangan minimal). Penelitian ini mengacu pada teori Verhar mengenai konsep fonem, jenis-jenis vokal, identitas fonem sebagai identitas pembeda. Hasil analisis data ialah vokal dalam bahasa Budong-Budong sebanyak lima, yaitu / i / / e/ , / a/ , / o/ , dan / u/ . A da vokal yang khas dalam bahasa Budong-Budong, yaitu / a/ . Vokal / a/ memiliki dua al ofon, yaitu [a] dan [ ]. Contoh alofon [a] ialah pada kata-kata/ ako/ [ako] 'apa', / babuah/ [babu:ah] 'dada', dan / bulampa/ [bulampa] 'paha'. Contoh alofon [ ] ialah pada kata-kata / aso:/] [_So:] 'rusuk', / kanding/ [k_ndC] 'dahi', dan / lima/ [lim ]'lima'.
\end{abstract}

Kata kunci: vokal, bahasa, Budong-Budong.

\begin{abstract}
TheBudong-Budong language is an al most extinct language. N umber of speakers of Budong-Budong language are 70 people. Therefore, this language should be prioritized for conservation. The efforts included in the conservation programe are the preparation of phonological, morphological, syntactic, and literary or orthographic systems. The problem of the research is to know any vowels are availablein Budong-Budong language. The purpose of this research is to find vowels contained in Budong-Budong language and their allophones that are expected to be useful for any preparation of its phonology system. Themethod used in this research is descriptive. $D$ ata collection is done by interview and recording. $D$ ata processing is done by the method of matching (referent and opponent referral tool) and themethod of distribution (with thetechnique of minimal pair opposition). This study refers to thetheory of $V$ erhar on the concept of phonemes, vowel types, and theidentity of phonemes as distinct identities. Theresult of data analysis is vowels in Budong-Budong as much as five, that are $/ \mathrm{i} /, / \mathrm{e} /, / \mathrm{a} /, / \mathrm{O} /$, and $/ \mathrm{u} /$. There is a special vowel in Budong-Budong language, i.e. /a/. The/a/vowel of Budong-Budong has two allophones, i.e. [a] and [_]. The examples of allophone[a] are such as in the following words: /ako/ [ako] 'what', /babuah/ [babu:ah] 'chest', and /bulampa/ [bulampa] 'thigh'. The examples of allophone [_] are such as in the following words: /aso?/ [_So?] 'rib', /kanding/ [k_ndG] 'forehead', dan /lima/ [lim_] 'five'.
\end{abstract}

Keyw ords: vocal, language, Budong-Budong.

\section{PEN DAHULUAN}

Undang-Undang Republik Indonesia Nomor 24 Tahun 2009 tentang Bendera,
Bahasa, dan Lambang Negara, serta Lagu Kebangsaan, Pasal 42 mewajibkan pemerintah untuk mengembangkan, membina, dan me- 
lindungi bahasa daerah agar tetap memenuhi kedudukan dan fungsinya dalam kehidupan bermasyarakat sesuai dengan perkembangan zaman dan agar tetap menjadi bagian dari kekayaan budaya Indonesia (Badan Pengembangan dan Pembinaan Bahasa, 2011). Dalam Peraturan Pemerintah Republik Indonesia N omor 57 Tahun 2014 tentang Pengembangan, Pembinaan, dan Pelindungan Bahasa dan Sastra, serta Peningkatan Fungsi Bahasa Indonesia (Badan Pengembangan dan Pembinaan Bahasa, 2016) Pasal 8 diatur bahwa pemerintah melaksanakan fasilitasi yang diperlukan untuk pengembangan, pembinaan, dan pelindungan bahasa dan sastra daerah sesuai dengan ketentuan peraturan perundang-undangan. Satu di antara delapan program prioritas Badan Bahasa ialah konservasi dan revitalisasi bahasa daerah (Sunendar, 2018). Dalam program konservasi ada upaya pencegahan atau perbaikan aspek bahasa yang rusak untuk menjamin kelangsungan bahasa itu. Upaya pencegahan dan perbaikan dapat dilakukan me lalui pendokumentasian sekaligus pengembangan bahasa bersangkutan, misal nya melalui penyusunan sistem fonologi, morfologi, sintaksis, dan sistem aksara atau ortografi (Badan Pengembangan dan Pembinaan Bahasa, 2017).

Bahasa Budong-Budong jumlah penuturnya 70 orang (Lewis, 2009:443). Menurut Suhaemi (2011:19), bahasa Budong-Budong merupakan bahasa yang hampir punah. Bahasa yang penuturnya hanya 70 orang dan dalam kondisi hampir punah selayaknya diprioritaskan untuk dikonservasi.

Upaya menyusun sistem fonologi, morfologi, dan sintaksis bahasa Budong-Budong sudah dilakukan dan dituangkan dalam buku dengan judul Kosakata D asar Bahasa Panasuan serta Tata Bahasa Ringkas Bahasa Panasuan dan Kosakata D asar Bahasa Tangkou serta Tata Bahasa Ringkas Bahasa Tangkou (Manda, 2002). Bahasa Tangkou ialah nama lain dari bahasa BudongBudong. Buku karya Manda itu merupakan tulisan ringkas. Perlu dilakukan upaya lebih lanjut dalam bentuk penelitian-penelitian mengenai fonem, pembentukan kata, proses morfofonologis, klausa, kalimat, dan lain-lain.

Berdasarkan latar belakang tersebut, rumusan masalah dalam penelitian ini ialah vokal apa saja yang terdapat dalam bahasa BudongBudong dan apa saja al ofonnya. Sementara itu, tujuan penelitian ini ialah menemukan vokalvokal yang terdapat dalam bahasa BudongBudong dan al ofon-alofonnya. Hasil penelitian ini diharapkan bermanfaat dalam upaya penyusunan sistem fonologi bahasa BudongBudong. Penelitian ini, dalam lingkup fonologi, dapat dijadikan dasar dalam penelitian morfologi dan sintaksis. Dengan demikian, hasil penelitian ini diharapkan dapat dijadikan referensi dalam penelitian morfologi dan sintaksis. Selain itu, hasil penelitian ini diharapkan dapat bermanfaat dalam upaya konservasi bahasa Budong-Budong.

Bahasa Budong-Budong dipergunakan oleh masyarakat Budong-Budong di Kabupaten Mamuju Tengah. Kabupaten tersebut merupakan pemekaran dari Kabupaten Mamuju. Wilayah Kabupaten Mamuju Tengah dahulu secara administratif hanyalah sebuah kecamatan bernama Kecamatan Budong-Budong dan termasuk dalam Kabupaten Mamuju. Waktu itu, Kecamatan Budong-Budong terdiri atas empat desa, yaitu Desa Babana, Lumu, BudongBudong, dan Karossa (Said, 2016:1).

Said (2016:2-5) menerangkan sejarah terbentuknya Kabupaten Mamuju Tengah bahwa Kabupaten Mamuju Tengah terbentuk melalui persetujuan DPR RI dalam sidang paripurna pada hari Jumat, tanggal 14 Desember 2012 di Jakarta. Pemerintahan Kabupaten Mamuju Tengah mulai berjalan efektif pada bulan Desember 2013. Terbentuknya Kabupaten Mamuju Tengah tidaklah dalam proses yang singkat, tetapi membutuhkan proses dan waktu yang panjang. Sebelum terbentuk Kabupaten Mamuju Tengah, ada program pembangunan nasional yang mulai dirintis sekitar tahun tujuh puluhan. Salah satu programnya 
ialah program trnasmigrasi. Kecamatan Budong-Budong disurvei pada tahun 1979. Hasil survei ialah Kabupaten Mamuju ditetapkan sebagai daerah tujuan penempatan program transmigrasi dan Kecamatan Budong-Budong sebagai salah satu tujuan penempatan warga transmigran. $\mathrm{Hal}$ itu dilakukan dengan membuka unit permukiman transmigrasi (UPT) dan menempatkan warga transmigran dari daerah asal, yaitu Jawa, Bali, NTT, NTB, dan dari Sulawesi Selatan. Pembentukan UPT tersebut dibina oleh Departemen Transmigrasi selama lima tahun dan setiap warga mendapatkan lahan seluas 2 hektare terdiri atas Iahan usaha dan pekarangan serta pembinaan usaha ekonomi berupa pertanian dan usaha perdagangan umum serta jasa. Hal itu dengan tujuan agar warga transmigran mandiri se bagai persiapan untuk diserahkan kepada Pemerintah Kabupaten Mamuju dengan status wilayah pemerintahan desa. Selain UPT di atas, di Kecamatan Budong-Budong terdapat 4 desa induk sebagai wilayah pembentukan unit pemukiman transmigrasi dan penempatan warga transmigran dari daerah asal, yaitu (1) Desa Babana, (2) Desa Budong-Budong, (3) Desa Lumu, dan (4) Desa Karossa. Dengan adanya perubahan status wilayah akibat pembukaan pemukiman transmigrasi, pemekaran, dan pembentukan desa, secara otomatis diikuti pertambahan penduduk. Di samping pertambahan penduduk akibat transmigrasi spontan dari Sulawesi Selatan, pelayanan masyarakat di bidang pemerintahan mengalami rentang kendali yang luas dan tidak mampu dijangkau. Oleh karena itu, pada tahun 1995 di Kecamatan Budong-Budong dibentuk perwakilan kecamatan untuk mendekatkan pelayanan, yaitu (1) Perwakilan Kecamatan Topoyo, (2) Perwakilan Kecamatan Karossa, dan (3) Perwakilan Kecamatan Pangale. Selain itu, tahun 2003 dibentuk Kecamatan Tobadak sebagai pemekaran dari Kecamatan Budong-Budong. Sekarang, Kabupaten Mamuju tengah terdiri atas lima kecamatan, yaitu Kecamatan Budong-
Budong, Topoyo, Karossa, Pangale, dan Tobadak. Kecamatan Budong-Budong terdiri atas 11 desa, Kecamatan Topoyo terdiri atas 15 desa, Kecamatan Karossa terdiri atas 11 desa dan 2 UPTD, Kecamatan Pangale terdiri atas 8 desa, dan Kecamatan Tobadak terdiri atas 8 desa.

Masyarakat Mamuju tengah merupakan masyarakat heterogen. Menurut Kampil (2016) hampir seluruh puak Nusantara berdiam di Mamuju Tengah. Puak-puak dari luar datang di Mamuju Tengah, yang terbanyak ialah melalui program transmigrasi, seperti dari Jawa dan Bali. Selain itu, ada juga tansmigrasi spontan terutama orang-orang Mandar, Bugis dan Makassar.

Masyarakat adat Budong-Budong memakai bahasa sendiri. Bahasa itu disebut bahasa Budong-Budong dan nama lainnya ialah bahasa Tangkou. Manda (2002) menyebut bahasa itu bahasa Tangkou. Namun, Manda juga mengatakan bahwa sebutan lain untuk bahasa Tangkou ialah bahasa Budong-Budong. Masyarakat adat Budong-Budong asal-usulnya dari perkampungan yang diberi nama "Tangkou". Perkampungan ini dahulu termasuk wilayah Kecamatan Budong-Budong. Sekarang, perkampungan itu masuk dalam wilayah Kecamatan Topoyo yang dilewati oleh Sungai Budong-Budong. Oleh karena itu, bisa dipahami bahwa bahasa mereka dinamai bahasa Budong-Budong dan nama lainnya ialah bahasa Tangkou. Berikut ini foto Sungai Budong-Budong pada suatu sore.

\section{Sungai Budong-Budong pada Suatu Sore}

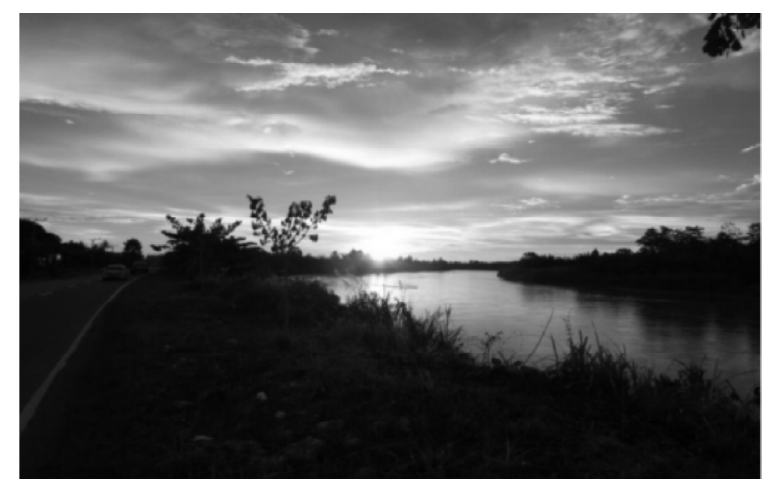

Dok. Mardi Nugroho 
Sama dengan tulisan Manda di atas, masyarakat adat Budong-Budong, menurut Said (2016:6) asal-usulnya dari perkampungan yang diberi nama Tangkou. Mereka dahulu tiba di hulu sungai dan secara berkelompok membuka perkampungan. Perkampungan itu diberi nama Tangkou karena saat dibuka perkampungan banyak tumbuhan sayur paku yang dalam bahasa Budong-budong disebut "tangkou".

Bahasa Budong-Budong juga disebut bahasa Tangkou. Bahasa Budong-Budong dituturkan di Dusun Tangkou, Tangkou Indah, dan Bumi Tangkou, Desa Tabolang, Kecamatan Topoyo, Kabupaten Mamuju Tengah, Provinsi Sulawesi Barat. Hampir semua penutur bahasa Budong-Budong ialah multibahasawan. Mereka menuturkan bahasa BudongBudong, bahasa Indonesia, dan bahasa Topoyo. Selain itu, banyak juga yang menguasai bahasa Mamuju. Jumlah penutur bahasa BudongBudong jauh lebih sedikit daripada jumlah penutur bahasa Topoyo dan jumlah penutur bahasa Mamuju. Kondisi multibahasawan dan jumlah penutur bahasa Budong-Budong yang jauh lebih sedikit itu bisa mengakibatkan pe nurunan daya hidup atau vitalitas bahasa Budong-Budong. Ibrahim (2009:95) yang mengutip tulisan Summer Institute of Linguistic menyebut bahwa salah satu hal yang mendorong kecepatan kepunahan bahasa ialah penggunaan bahasa lain secara regular dalam latar budaya yang beragam.

Desa Tabolang dilewati oleh jalan Trans Sulawesi yang menghubungkan Provinsi Sulawesi Selatan, Sulawesi Barat, Sulawesi Tengah, Gorontalo, dan Sulawesi Utara. Di Desa Tabolang ada permukinan transmigran dari Pulau Jawa dan Bali. Di dekat Desa Tabolang ada pasar Topoyo yang merupakan pasar terbesar di Kabupaten Mamuju tengah. Berikut ini ialah foto sisi-sisi pasar Topoyo dan aneka ragam barang yang dijual.
Pasar Topoyo dan A neka

Ragam Barang yang D ijual
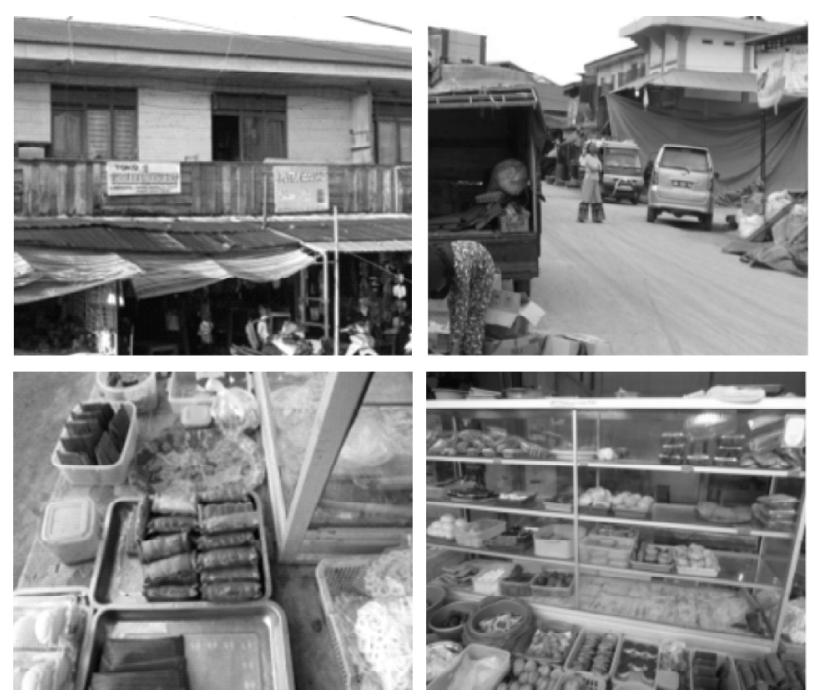

Dok. Mardi Nugroho

Para pedagang pasar Topoyo dan aneka barang yang dijual (termasuk aneka kudapan yang dijual) yang berasal dari Topoyo, dari Mamuju, dari Sulawesi Selatan, dari Jawa, dan dari daerah lain itu memberikan sedikit gambaran keragaman suku bangsa, bahasa, serta adat-istiadat yang berinteraksi dan saling berpengaruh. Keberadaan jalan trans Sulawesi, permukiman transmigran, dan pasar Topoyo itu bisa mengakibatkan penurunan daya hidup bahasa Budong-Budong.

\section{TEORI DAN METODE}

Penelitian ini mengacu pada teori Verhar (2006). Verhar menjelaskan konsep fonem, jenis-jenis vokal, identitas fonem sebagai identitas pembeda secara berturut-turut di bawah ini.

Ada dua kelas bunyi bahasa, konsonan dan vokal. Konsonan ialah bunyi yang dihasilkan dengan mempergunakan artikulasi pada salah satu bagian alat bicara. Vokal ialah bunyi bahasa yang dihasilkan dengan melibatkan pitapita suara-tanpa penyempitan atau penutupan apa pun pada tempat pengarikulasian manapun. Selain konsonan dan vokal, ada bunyi bahasa di antara konsonan dan vokal ialah semivokal. 
Vokal ialah bunyi bahasa yang dihasilkan dengan melibatkan pita-pita suara-tanpa penyempitan atau penutupan apa pun pada tempat pengartikulasian mana pun. Jenis vokal tergantung pada "bangun mulut" - kecuali "lamanya" atau "kuantitas" vokal; semua sifat vokal lain menyangkut "kualitas" vokal. Menurut kualitas dan kuantitas tersebut, vokal dapat digolongkan sebagai berikut.

[i] Vokal tinggi, vokal rendah, dan vokal tengah.

Penggolongan ini ialah penggolongan menurut tinggi rendahnya vokal, yaitu menurut tinggi rendahnya posisi lidah terhadap langitlangit. Misalnya, untuk mengucapkan [a] seperti dalam kata "asuh", posisi lidah ialah rendah terhadap langit-langit. Dalam mengucapkan [i] (hidup), lidah posisinya tinggi, dekat pada langit-langit. Sementara itu, dalam mengucapkan [ə] (lebih), posisi lidah ialah sekitar di tengah posisi tinggi dan posisi rendah.

[ii] Vokal depan, vokal belakang, dan vokal madya.

Depan-belakangnya vokal tergantung dari posisi lidah juga. Bila lidah itu "datar" permukaannya, vokal bersangkutan ialah vokal "depan", seperti halnya dengan vokal [a] dan [i]. Sebaliknya, apabila lidah lebih rendah di belakang, vokal bersangkutan merupakan vokal belakang, seperti vokal [o] dalam kata obat dan o dalam kata pokok. Posisi lidah menurut depan belakangnya dapat juga berupa kuranglebih di antara depan dan belakang. Vokal de ngan posisi lidah demikian ialah vokal madya, seperti [ə] dalam kata tengah dan [A] dalam kata Inggris "but".

\section{[iii] Vokal bundar dan vokal tak bundar}

Perbedaan bangun mulut dalam hal ini ialah pebedaan menurut bundar tidaknya kedua bibir. Misalnya, vokal [i] merupakan vokal yang tak bundar dan bila posisi lidah menurut tinggi rendahnya serta menurut depan-belakangnya dipertahankan, tetapi dengan memperbundar bibir, hasilnya ialah vokal [ü], seperti dalam kata Jerman grün 'hijau', atau kata Belanda duwen 'mendorong'.

[iv] Vokal panjang dan vokal pendek.

Perbedaan ini menyangkut lamanya (atau "kuantitas") pelafalan vokal. Misal nya, [u] dalam [ù] dalam kata Inggris full ialah vokal pendek, sedangkan [u] dalam kata Inggris fool ialah panjang.

[v] Vokal nasal (atau vokal sengauan) dan vokal oral.

Dalam pengucapan oral, seluruh arus udara keluar melalui mulut dan rongga hidung tertutup (dengan menggerakkan langit-langit lunak ke dinding belakang rongga kerongkongan). Semua vokal nomor [i]_[iv] di atas ialah vokal oral. Sebaliknya dalam pengucapan vokal sengauan sebagian dari arus udara keluar melalui rongga mulut, sebagian yang lain melalui rongga hidung (langit-langit diturunkan sedikit untuk memungkinkan bangun mulut yang demikian). Contoh vokal nasal banyak ditemukan dalam bahasa Prancis, yaitu [l] dalam un 'satu', [o] dalam oncle 'paman', [a] dalam bande 'rombongan', [æ] dalam ainsi 'demikian'.

[vi] Vokal tunggal dan vokal rangkap dua atau diftong.

Semua vokal nomor [i]-[v] ialah vokal yang pelafalannya tidak melibatkan perubahan bangun mulut selama pelafalan tersebut. Misalnya, dalam pelafalan [a], bangun mulut sama dari permulaan sampai akhir. Vokal seperti itu disebut vokal tunggal.

Dalam pelafalan vokal rangkap dua (diftong), setengah lamanya pelafalan vokal bangun mulut diubah. Misalnya, [au] dalam "kalau" ialah sebuah diftong: pelafalannya mulai dengan bangun mulut rendah-depan dan berakhir dengan bangun tinggi belakang. Contoh lain ialah dalam kata "balai", diftongnya [ai] mulai dengan bangun mulut rendahdepan dan berakhir dengan bangun tinggi depan. 
Dasar bukti identitas fonem ialah "fungsi pembeda" sebagai sifat khas fonem itu. Contohnya ialah tentang kata "rupa" dan "lupa". Satu-satunya perbedaan di antara dua kata dalam bahasa Indonesia itu ialah menyangkut bunyi pertama, yaitu [I] dan [r]. Karena semua yang lain dalam pasangan kedua kata itu sama, pasangan itu disebut "pasangan minimal": perbedaan dalam pasangan itu ialah "minimal" (disebut "perbedaan minimal"). Dengan perkataan lain, perbedaan antara [I] dan [r] ialah yang membedakan (dari sudut analisis bunyi) rupa dan lupa. Oleh karena itu, [I] dan [r] dalam bahasa Indonesia merupakan fonem-fonem yang berbeda identitasnya. Sebaliknya dalam bahasa Jepang, bunyi yang secara fonetis dapat berupa [I] dapat juga berupa [r] tidak pernah membedakan dua kata dalam pasangan minimal. Oleh karenaitu, kedua bunyi itu tidak merupakan fonem-fonem yang berbeda dalam bahasa Jepang.

Metode yang digunakan dalam penelitian ini bersifat deskriptif. Pengumpulan data dilakukan dengan wawancara terstruktur dan dengan perekaman. Penentuan informan dilakukan dengan mempertimbangkan faktor usia, jenis kelamin, bahasa ibu, kemampuan berbahasa Indonesia lisan, kesempurnaan alat ucap, dan tidak buta huruf. Untuk mengetahui bunyi vokal dilakukan wawancara dan pe rekaman terhadap penutur bahasa BudongBudong. Dilakukan juga perekaman peristiwa bahasa untuk memperoleh korpus data. Informan diminta mengucapkan kata yang merupakan kata target yang sudah ditentukan. Pe nentuan data dengan mempertimbangkan ke perluan penentuan fonem dan alofon serta fonotaktik. Untuk menjaga naturalitas ujaran, informan diminta mengucapkan berulangulang dan bila perlu dicek dengan informan lain. Pengolahan data dilakukan dengan me tode padan (alat penentunya referen dan mitra wicara) dan metode distribusional (dengan teknik oposisi pasangan minimal). Penamaan metode padan ini mengikuti Subroto dan Sudaryanto. Menurut Subroto (1992: 55-56) metode padan sering juga disebut dengan metodeidentitas, yaitu metodeyang dipakai untuk menentukan identitas satuan lingual tertentu dengan alat penentu di luar bahasa, terlepas dari bahasa, dan tidak menjadi bagian dari bahasa yang bersangkutan. Menurut Sudaryanto (1993: 13-14), dalam metode padan ada lima teknik, yaitu (1) teknik referensial, alat penentunya ialah kenyataan yang ditunjuk oleh bahasa atau referen bahasa; (2) teknik fonetis artikulatoris, alat penentunya organ pembentuk bahasa atau organ wicara; (3) teknik translational, alat penentunya bahasa lain; (4) teknik ortografi, alat penentunya pengawet bahasa, perekam atau tulisan; dan (5) teknik pragmatis, alat penentunya ialah mitra wicara. Penamaan metode distribusional ini mengikuti Subroto. Menurut Subroto (1992: 63), metode distribusional ialah metode analisis linguistik yang dikembangkan oleh linguistik strukturalisme model Amerika. Metode distribusional dibagi menjadi teknik urai unsur terkecil, teknik urai unsur langsung, teknik oposisi (dalam bidang fonologi ialah teknik oposisi pasangan minimal), teknik pergantian, teknik perluasan, teknik pelepasan, teknik penyisipan, teknik pembalikan urutan, dan teknik parafrasis.

\section{HASIL DAN PEMBAHASAN}

\section{Deskripsi Vokal}

Dalam penelitian ini, ditemukan lima vokal, yaitu / i/ , / e/ , / a/ , / o/, dan / u/. Vokal bahasa Budong-Budong dan distribusinya dalam kata dapat dilihat pada tabel berikut ini. 
TABEL 1VOKAL DAN DISTRIBUSINYA DALAM KATA

\begin{tabular}{|c|c|c|c|}
\hline \multirow[t]{2}{*}{ Fonem } & \multicolumn{3}{|c|}{ Posisi } \\
\hline & Awal & Tengah & Akhir \\
\hline /i/ & $\begin{array}{l}\text { /idua/ [idua] 'kedua' } \\
\text { /indo?/ [indb?] } \\
\text { 'ibu' } \\
\text { /isanna/ [iSan:a] } \\
\text { 'sambal' } \\
\text { /isung/ [iSUG 'lesung' } \\
\text { /italu/ [italu] 'tiga' } \\
\text { /itoja/ [itoja] } \\
\text { 'diayun' }\end{array}$ & $\begin{array}{l}\text { /kanding/ [k_ndG } \\
\text { 'dahi' } \\
\text { /lima/ [lim_ / 'lima' } \\
\text { /mangkaik/ [maGkai?] } \\
\text { 'guru' } \\
\text { /manippa/ [manip:a] } \\
\text { 'tipis' } \\
\text { /tai anging/ [tai vaGG } \\
\text { 'awan' } \\
\text { /tai likko/ [tai lik:o] } \\
\text { 'usus' }\end{array}$ & $\begin{array}{l}\text { /garagaji/ [garagaji] } \\
\text { 'gergaji' } \\
\text { /loppi/ [lop:i] 'perahu' } \\
\text { /makdihi/ [ma?dhi] } \\
\text { 'alir (me-)' } \\
\text { /sappi/ [Sap:i] 'sapi' } \\
\text { /sulli/ [Sul:i] } \\
\text { 'suling' } \\
\text { /tahannasi/ [tahan:aSi] } \\
\text { 'nenas' }\end{array}$ \\
\hline /e/ & /eteng/ [eteG 'pagar' & $\begin{array}{l}\text { /dedekko/ [dedak:o] } \\
\text { 'mangga hutan' } \\
\text { /kalleda?/ [kal:eda?] } \\
\text { 'ketiak' } \\
\text { /sende/ [Sende] 'membuai' } \\
\text { /tekeng/ [tekeG } \\
\text { 'tongkat' }\end{array}$ & $\begin{array}{l}\text { /bahhebe/ [bah:ebe] } \\
\text { 'halaman' } \\
\text { /bosse/ [boS:e] 'dayung' } \\
\text { /kalae/ [kalaE] } \\
\text { 'tubuh' } \\
\text { /mande/ [mande] } \\
\text { 'makan' } \\
\text { /pahe/ [pahe] 'padi' }\end{array}$ \\
\hline & & $\begin{array}{l}\text { /hengi/ [hEG] 'malam' } \\
\text { /kabenni/ [kabEn:i] } \\
\text { 'mangga' } \\
\text { /nene?/ [nEnE? 'kakek, } \\
\text { nenek' } \\
\text { /mangempei/ [maCEmpEi] } \\
\text { 'mengasuh' } \\
\text { /tengke/ [tEGE] } \\
\text { 'angkat' }\end{array}$ & $\begin{array}{l}\text { /ambe/ [ambE] 'ayah' } \\
\text { /pituhe/ [pituhE] 'kipas } \\
\text { anglo' } \\
\text { /umbamene/ } \\
\text { [umbamEnE] } \\
\text { 'bagaimana' } \\
\text { /tuhe/ [tuhE] 'tiup' } \\
\text { /uppe/ [up:E] 'keladi' }\end{array}$ \\
\hline & & $\begin{array}{l}\text { /besumau/ [b| Suma+] } \\
\text { 'durian' } \\
\text { /sembayang/ [S| mbay_G } \\
\text { 'sembahyang' } \\
\text { /setangngah/ [s| taGah] } \\
\text { 'setengah' }\end{array}$ & \\
\hline
\end{tabular}




\begin{tabular}{|c|c|c|c|}
\hline$/ \mathrm{a} /$ & $\begin{array}{l}\text { /ako/ [ako] } \\
\text { 'apa' } \\
\text { /ambe/ [ambE] 'ayah' } \\
\text { /anar [ano?] } \\
\text { 'anak' } \\
\text { /api/ [api] 'api' } \\
\text { /ajarang/ [ajar_G } \\
\text { 'kuda' } \\
\text { /atu/ [atu] 'atap' }\end{array}$ & $\begin{array}{l}\text { /babuah/ [babu:ah] } \\
\text { 'dada' } \\
\text { /garagaji/ [garagaji] } \\
\text { 'gergaji' } \\
\text { /ma?dihi/ [ma?dhi] } \\
\text { 'alir (me-)' } \\
\text { /saho/ [Saho] 'ular' } \\
\text { /tai anging/ [tai vaGG } \\
\text { 'awan' } \\
\text { /manippa/ [manip:a] } \\
\text { 'tipis' }\end{array}$ & $\begin{array}{l}\text { /isanna/ [iSan:a] } \\
\text { 'sambal' } \\
\text { /suna/ [Sun:a] 'sunat' } \\
\text { /bulampa/ [bulampa] } \\
\text { 'paha' } \\
\text { /kauha?a/ [kauha?a] } \\
\text { 'kedelapan' } \\
\text { /manippa/ [manip:a] } \\
\text { 'tipis' } \\
\text { /mesa/ [meS] 'satu' }\end{array}$ \\
\hline & $\begin{array}{l}\text { /aso?/[_So? } \\
\text { 'rusuk/ }\end{array}$ & $\begin{array}{l}\text { /canni? [c_n:i?] 'madu' } \\
\text { /hana?ang/ [hana?_G } \\
\text { 'bahu' } \\
\text { /kanding/ [k_ndG 'dahi' } \\
\text { /lamang/ [lam_G 'lemang' } \\
\text { /nangka/ [n_G_] 'nangka' } \\
\text { /ramba?/ [r_mb_] } \\
\text { 'mengapung' }\end{array}$ & $\begin{array}{l}\text { /balisa/ [baliS_] } \\
\text { 'keringat' } \\
\text { /kaleda/ [kaled]] } \\
\text { 'ketiak' } \\
\text { /lima/ [lim_] 'lima' } \\
\text { /nangka/ [n_G_] } \\
\text { 'nangka' } \\
\text { /pa?a/ [pa?] 'pahat' } \\
\text { /sumba/ [Sumb_] } \\
\text { 'layar' } \\
\text { /uga/ [ug_] 'gusi' }\end{array}$ \\
\hline \multirow[t]{2}{*}{$/ \mathrm{o} /$} & $\begin{array}{l}\text { /oho/ [oho] 'asap' } \\
\text { /ota?/ [ota?] 'otak' } \\
\text { /oso?/ [oSo? 'rusuk' }\end{array}$ & $\begin{array}{l}\text { /ano?/ [ano? 'anak' } \\
\text { /bobo?/ [bobo? 'nasi' } \\
\text { /kompo/ [kompo] 'tumpul' } \\
\text { /oso?/ [oSo?] 'rusuk' } \\
\text { /solong/ [solog 'alir' } \\
\text { /toso?/ [toSo?] 'tikam' }\end{array}$ & $\begin{array}{l}\text { /ako/ [ako] 'apa' } \\
\text { /oho/ [oho] 'asap' } \\
\text { /kompo/ [kompo] } \\
\text { 'tumpul' } \\
\text { /lempo/ [lempo] 'rumah' } \\
\text { /saho/ [Saho] 'ular' } \\
\text { /tai likko/ [tai lik:o] } \\
\text { 'usus' }\end{array}$ \\
\hline & & $\begin{array}{l}\text { /cindol/ [cindd] 'cendol' } \\
\text { /losi/ [lOSi] 'lusin' } \\
\text { /kodi/ [kOd] 'saya' } \\
\text { /mano? [manO: 'ayam' } \\
\text { /tallebo?[tal:ebO?] } \\
\text { 'centong' }\end{array}$ & $\begin{array}{l}\text { /buto/ [butg 'kemaluan } \\
\text { laki-laki' } \\
\text { /hulo/ [hulO 'bambu } \\
\text { kecil untuk seruling' } \\
\text { /kaderro/ [kader:G } \\
\text { 'kursi' } \\
\text { /imamanyo/ [imamang } \\
\text { 'pelan-pelan' }\end{array}$ \\
\hline
\end{tabular}




\begin{tabular}{|c|c|c|c|}
\hline$/ \mathrm{u} /$ & $\begin{array}{l}\text { /uga/ [ug_] 'gusi' } \\
\text { /uhar [uha?] 'urat' } \\
\text { /umbamene/ } \\
\text { [umbamEnE] } \\
\text { 'bagaimana' } \\
\text { /unung/ [unuG } \\
\text { 'keenam' } \\
\text { /uppa? [up:a? 'empat' }\end{array}$ & $\begin{array}{l}\text { /bu?a/ [buRu] } \\
\text { 'tulang' } \\
\text { /babuah/ [babu:ah] } \\
\text { 'dada' } \\
\text { /duhung/ [duhuG } \\
\text { 'jarum' } \\
\text { /janggu'/ [jaGou?] } \\
\text { 'janggut' } \\
\text { /sumba/ [Sumb] } \\
\text { 'layar' } \\
\text { /tuhe/ [tuhE] 'tiup' }\end{array}$ & $\begin{array}{l}\text { /atu/ [atu] 'atap' } \\
\text { /bu?u/ [buRu] 'tulang' } \\
\text { /hapu/ [hapu] 'dapur' } \\
\text { /salimu/ [Salimu] } \\
\text { 'selimut' } \\
\text { /sumpu/ [Sumpu] } \\
\text { 'junjung' } \\
\text { /susu/ [SuSu] 'tetek' }\end{array}$ \\
\hline & & $\begin{array}{l}\text { /isung/ [iSUG 'lesung' } \\
\text { /sungkung/ [SUGUG } \\
\text { 'bibir' }\end{array}$ & \\
\hline
\end{tabular}

Tabel 1 menunjukkan bahwa semua vokal bahasa Budong-Budong, yaitu / i/ , / e/ , a/ , o/ dan / u/ dapatmenduduki posisi awal, tengah, maupun akhir kata. Namun, data yang ditemukan untuk posisi awal, tengah, dan akhir untuk kelima vokal itu ada yang banyak ada yang sedikit.

Fonem / i/ dapat berposisi di awal, tengah, dan akhir kata. Data yang ditemukan baik pada posisi awal, tengah, maupun akhir kata banyak.

Fonem/ e/ dapat berposisi di awal, tengah, dan akhir kata. Namun, fonem / e/ yang berposisi di awal hanya ditemukan dalam satu kata, yaitu / eteng/ [eteG] 'pagar'. Sementara itu, yang berposisi di tengah dan akhir kata banyak ditemukan.

Fonem/ a/ dapat berposisi di awal, tengah, dan akhir kata. Data yang ditemukan baik pada posisi awal, tengah, maupun akhir kata banyak.

Fonem/ o/ dapat berposisi di awal, tengah, dan akhir kata. Data yang ditemukan lebih banyak fonem / o/ yang berposisi di tengah dan akhir kata.
Fonem / u/ dapat berposisi di awal, tengah, dan akhir kata. Penelitian ini menemukan sedikit data fonem / u/ yang berposisi di awal kata dan banyak datafonem / u/ yang berposisi di tengah dan akhir kata.

Dalam hal variasi bunyi, tidak ada variasi bunyi pada fonem / i/ . Sementara itu, pada fonem / e/ , a/ , / o/ dan / u/ ada variasi bunyi.

Fonem / e/ teralisasi dalam bunyi $[\epsilon],[E]$, dan [| ]. Akan tetapi, belum diketahui perbedaan posisi masing-masing bunyi itu dalam kata. Penelitian ini menemukan banyak realisasi bunyi $[\epsilon]$ dan [E] serta tiga realisasi bunyi [l] dalam kata, yaitu / besumau/ [k| Suma+] 'durian', / sembayang/ [S| mbay_C] 'sembahyang', dan / setangngah/ [S| taC:ah] 'setengah'.

Fonem / a/ memiliki dua alofon, yaitu [a] dan [_]. Alofon [a] terdapat pada posisi penultima (sebelum akhir) kata yang diikuti oleh konsonan / h/ , / r/ , / s/ , atau / ?/. Beberapa contohnya ialah pada kata-kata di bawah ini. / panah/ [panah] 'panah' / kamar/ [kamar] 'kamar' / lingkuas/ [licku+aS] 'lengkuas' / kalleda?/ [kal:edai] 'ketiak' 
/ katuppa?/ [katup:ai] 'ketupat'

/ota'/ [otai] 'otak'

/uhail [uha?] 'urat'

Sementara itu, alofon [_] terdapat pada posisi penultima (sebelum akhir) kata yang diikuti oleh konsonan / ng/ . Beberapa contohnya ialah pada kata-kata di bawah ini.

/ ajarang/ [ajar_C] 'kuda'

/ hana?ang/ [hana? C] 'bahu'

/ hatang/ [hat_C] 'batang'

/ hotang/ [hot_C] 'tempat beras'

/ lamang/ [lam_C] 'lemang'

/ larong/ [lar_C] 'larang'

/ sembayang/ [S| mbay_C] 'sembahyang'.

Fonem / o/ teralisasi dalam dua bunyi, yaitu [o] dan [C]. Penelitian ini menemukan banyak realisasi bunyi [o] maupun realisasi bunyi [C] dalam kata.

Vokal / u/ terealisasi dalam dua alofon, yaitu [u] dan [U]. Penelitian ini menemukan banyak realisasi bunyi $[u]$ serta dua realisasi bunyi [U] dalam kata, yaitu dalam kata isung/ [iSUG] 'lesung' dan/ sungkung/ [SUGKUC] 'bibir'.

\section{Klasifikasi Bunyi Bahasa (Vokoid)}

Berdasarkan teori Verhar di atas dengan sedikit modifikasi, penulis membuat klasifikasi bunyi bahasa Budong-Budong. Istilah yang biasa digunakan dalam bidang fonetik ialah vokoid, sedangkan istilah yang biasa digunakan dalam bidang fonologi atau fonemik ialah vokal. Oleh karenaitu, dalam klasifikasi, bunyi bahasa penulis sebut vokoid. Hal itu karenaada vokal yang terdiri atas dua alofon yang tidak dapat dimasukkan dalam klasifikasi yang sama. Dalam bahasa Budong-Budong, vokal / a/ memiliki dua alofon, yaitu [a] (dalam klasifikasi termasuk rendah-depan) dan [_] (dalam klasifikasi termasuk rendah-belakang). Adapun klasifikasi vokoid bahasa Budong-Budong dapat dilihat pada tabel berikut.
TABEL 2KLASIFIKASI VOKOID BAHASA BUDONG-BUDONG

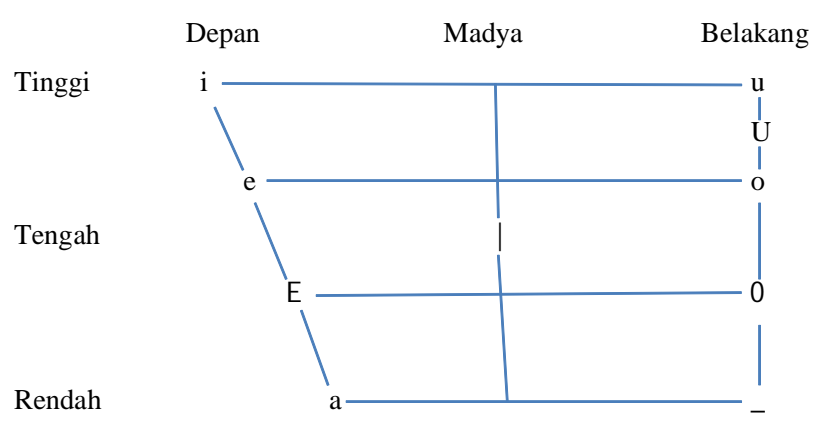

Tabel 2 melengkapi keterangan di atas. Dalam hal tinggi-rendah, vokoid-vokoid [i], [u], dan [U] diklasifikasikan sebagai vokoid tinggi; vokoid-vokoid $[e],[0],[]],[E]$, dan $[C]$ diklasifikasikan sebagai vokoid tengah; serta vokoid-vokoid [a] dan [_] diklasifikasikan sebagai vokoid rendah. Dalam hal depanbelakang, vokoid-vokoid [i], [e], [E], dan [a] diklasifikasikan sebagai vokoid depan; vokoid [l] d diklasifkasikan sebagai vokoid madya; serta vokoid-vokoid [u], [o], [C], dan diklasifikasikan [_] sebagai vokoid belakang.

Vokoid-vokoid [e], [E], dan [l] merupakan satu fonem, meskipun [e], [E] termasuk vokoid depan dan [l] termasuk vokoid madya. Selain itu, vokoid [e] lebih tinggi daripada[E] dan [l] ], serta [l] lebih tinggi daripada [E]. Vokoidvokoid [o] dan $[\mathrm{C}]$ merupakan satu fonem, vokoid [o] lebih tinggi daripada [C]. Vokoidvokoid [a] dan [_] merupakan satu fonem meskipun [a] termasuk vokoid depan dan [_] termasuk vokoid belakang.

\section{PENUTUP}

Dalam penelitian ini, ditemukan lima vokal, yaitu / i/ , / e/ , / a/, / o/ dan / u/ . Ada vokal yang khas dalam bahasa Budong-Budong, yaitu / a . Vokal / a/ memiliki duaalofon, yaitu [a] dan [_]. Contoh alofon [a] ialah pada katakata / ako/ [ako] 'apa', / atu/ [atu] 'atap', / babuah/ [babu:ah] 'dada', / garagaji/ [garagaji] 'gergaji', / suna/ [Sun:a] 'sunat', dan / bulampa/ [bulampa] 'paha'. Contoh alofon [_] 
ialah pada kata-kata / aso?/ [_So:] 'rusuk' , / kanding/ [k_ndC] 'dahi', / lamang/ [lam_C] 'lemang', / kaleda/ [kaled] 'ketiak', dan / lima/ [lim_] 'lima'.

Penelitian ini baru merupakan langkah kecil. Masih banyak misteri yang belum terkuak dalam bahasa Budong-Budong. Waktu yang tersedia untuk pengumpulan data sangat terbatas. Selain itu, semua penutur bahasa BudongBudong yang tersisa ialah multibahasawan. Mereka biasa bertutur dalam bahasa Indonesia dan bahasa Topoyo. A da juga yang menguasai bahasa Mamuju. Mereka sering lupa kata-kata dalam bahasa Budong-Budong. Kalau diminta menyebutkan kata dalam bahasa Budong-Budong sering ada yang disebutkan ialah bahasa Topoyo atau bahasa Mamuju. Pernah juga, mereka diminta menyebutkan kata dalam bahasa Budong-Budong, ternyata setelah diverifikasi yang disebutkan ialah kata dalam bahasa Bugis. Di antara mereka pun kadang-kadang Iama dalam mencapai kesepakatan perihal sebuah kata, apakah termasuk bahasa BudongBudong atau bukan (bisa bahasa Topoyo bisa bahasa Mamuju). Oleh karena itu, penelitian ini merekomendasikan agar dilakukan langkahlangkah selanjutnya untuk menyelamatkan bahasa Budong-Budong.

\section{DAFTAR PUSTAKA}

Badan Pengembangan dan Pembinaan Bahasa. 2011. U ndang-U ndang Republik Indonesia Nomor 24 Tahun2009 tentang Bendera, Bahasa, dan Lambang N egara, serta Lagu Kebangsaan.

Badan Pengembangan dan Pembinaan Bahasa, Kementerian Pendidikan dan Kebudayaan. 2016. Salinan Peraturan Pemerintah Republik Indonesia Nomor 57 Tahun 2014 tentang Pengembangan, Pembinaan, dan Pelindungan Bahasa dan Sastra, serta Peningkatan Fungsi Bahasa Indonesia.

Badan Pengembangan dan Pembinaan Bahasa. 2017. Pedoman Konservasi dan Revitalisasi.
Ibrahim, Gufran Ali. 2009. M etamorfosa Sosial dan Kepunahan Bahasa. Ternate: Lembaga Penerbitan Universitas Khairun.

Kampil, H. Abd. Rasyid. 2016. “Mendulang Fenomena Budaya di Bumi Lalla Tasisara' Kabupaten Mamuju Tengah". Makalah disampaikan dalam Dialok Budaya Kabupaten Mamuju Tengah pada tanggal 7 Desember.

Lewis, M. Paul (Editor). 2009. Ethnologue Languages of the World. Dallas: SIL International.

Manda, Marthen L., Masao Yamaguchi, dan Hirotake Nakashima. 2002. Kosakata D asar Bahasa Panasuan serta Tata Bahasa Ringkas Bahasa Panasuan dan Kosakata Dasar Bahasa Tangkou serta Tata Bahasa Ringkas Bahasa Tangkou. Osaka: ELPR.

Said, Herly. 2016. "Mengenal Seni dan Budaya Lokal di Kabupaten Mamuju Tengah". Makalah disampaikan dalam Seminar Budaya Lokal di Kabupaten Mamuju Tengah pada tanggal 14 Desember.

Subroto, D. Edi. 1992. Pengantar M etode Penelitian Linguistik Struktural. Surakarta: Sebelas Maret University Press.

Sudaryanto. 1993. M etode dan A neka Teknik A nalisis Bahasa. Yogyakarta: Duta Wacana University Press.

Suhaemi, Eem. dkk. 2011. “Vitalitas, Dokumentasi, dan Inventarisasi Bahasa Budong Budong di Mamuju, Sulawesi Barat", Laporan Penelitian Badan Pengembangan dan Pembinaan Bahasa.

Sunendar, Dadang. 2018. "Kebijakan Penelitian Bahasa" Makalah Bimtek Pengolahan Data Lapangan, Badan Pengembangan dan Pembinaan Bahasa bekerja sama dengan MLI, 16-17 April.

Verhar. J.W.M. 2006. A sas-A sas Linguistik U mum. Yogyakarta: Gadjah Mada University Press. 
